\title{
Decreased expression of the SPOP gene is associated with poor prognosis in glioma
}

\author{
DACHENG DING, TAO SONG, WU JUN, ZEMING TAN and JIASHENG FANG
}

Department of Neurosurgery, Xiangya Hospital, Central South University, Changsha, Hunan 410008, P.R. China

Received August 23, 2014; Accepted October 3, 2014

DOI: 10.3892/ijo.2014.2729

\begin{abstract}
This study suggests that speckle-type POZ protein (SPOP) may be a tumor suppressor gene and its prognostic value in human glioma. Real-time quantitative RT-PCR (qRT-PCR), western blotting, and immunohistochemical staining were used to examine SPOP expression in glioma tissues and normal brain (NB) tissues. The relationships between the SPOP expression levels, the clinicopathological factors, and patient survival were investigated. The molecular mechanisms of SPOP expression and its effects on cell viability, migration and invasion were also explored by MTT assay, wound-healing assays and Transwell assay. SPOP mRNA and protein levels were downregulated in glioma tissues compared to NB. Immunohistochemical staining results showed low expression in $62.2 \%$ (61/98) of glioma samples, while high expression in $75 \%(9 / 12)$ of NB samples, and the difference was statistically significant $(\mathrm{P}=0.014)$. In addition, decreased SPOP was associated disease progression in glioma samples, the expression level of SPOP was positively correlated with mean tumor diameter (MTD) $(\mathrm{P}=0.021)$ and the status of tumor grade and histological type (WHO I, II, III and IV) $(\mathrm{P}=0.032)$ in glioma patients. Additionally, the overall survival of patients with low SPOP expression was significantly worse than that of SPOP-high patients $(\mathrm{P}=0.001)$. In vitro overexpression of SPOP markedly inhibited cell viability, migration and invasion in vitro. These findings suggest that SPOP has potential use as novel biomarker of glioma and may serve as an independent predictive factor for prognosis of glioma patients.
\end{abstract}

\section{Introduction}

Glioma is the most common brain tumor in adults. Its ability to evade immune surveillance and impede antitumor responses may lead to sustained growth and enhanced malignancy (1). Despite attempts at treatment using surgical resection, radiation and chemotherapy with the alkylating agent temozolomide, the

Correspondence to: Dr Jiasheng Fang, Department of Neurosurgery, Xiangya Hospital, Central South University, Changsha, Hunan 410008, P.R. China

E-mail: fangjiashengns@sina.com

Key words: glioma, SPOP, prognosis survival rates of patients with high-grade gliomas are $<10 \%$ at 5 years (2). Since current treatment gained little benefit in the setting of glioma, greater attention has been paid to the expression of specific molecular markers with the goal of understanding the main molecular mechanisms of this malignancy and determining their possible prognostic significance.

The speckle-type POZ protein (SPOP) has been identified as an autoantigen in scleroderma patients and a constituent of nuclear speckles in human cells. SPOP is a 374-amino acid protein that contains a $\mathrm{C}$-terminal POZ (poxvirus and zinc finger) domain (also known as a BTB domain) and an N-terminal MATH (meprin and TRAF-C homology) domain (3). The C-terminal POZ domain of SPOP interacts directly with Cullin3-based E3 ubiquitin ligase complex, while its N-terminal MATH domain interacts with various substrates of the complex. In mammals, the MATH-BTB protein SPOP has been linked to ubiquitination of MacroH2A, to regulate its deposition on the inactive X-chromosome (4), and has been shown to act as an adaptor of Daxx in the ubiquitination process involving Cul3-based ubiquitin ligase in the Hedgehog/Gli signaling pathway, to regulate transcriptional repression of pro-apoptotic proteins such as p53 (5). Recent genome-wide somatic mutation analyses identified that SPOP gene encoding the speckle-type POZ protein was frequently mutated in some human cancers, including prostate and endometrial carcinomas (6-9). Ubiquitin modifications regulate a wide variety of cellular processes and more or less are involved in cancer pathogenesis (10). Also, earlier observations that SPOP, an adaptor for Cul3-based ubiquitination (6-11), may be a TSG led us to further analyze whether SPOP gene mutations occurred in other common malignancies. In one recent study, we found that only $0.2 \%$ of hematologic malignancies and none of the solid tumors (breast, lung and liver cancers) harbored SPOP somatic mutations, suggesting that somatic mutation of SPOP gene may not play a role in the development of breast, lung, and liver cancers, and acute leukemias.

In addition to the somatic mutation, altered expression of ubiquitination related genes is observed in many cancers $(12,13)$. An earlier study described analyzed SPOP protein was expressed in normal gastric, colonic and prostate epithelial cells, whereas it was lost in $30 \%$ of gastric cancer, $20 \%$ of colorectal cancer and $37 \%$ of prostate cancer (14).

SPOP plays a key role in the development of peripheral and central nervous system and tumorigenesis (15). Furthermore, it was recently demonstrated that knockdown of Drosophila 
SPOP mRNA expression by RNA interference (RNAi) and P-element insertion mutagenesis of the SPOP resulted in severe and consistent disruption of the peripheral and the CNS (16). Also, our findings support the genomewide linkage results pointing towards disease loci on 17q12-21.32 and 12p13.33-12.1 for glioma risk in families. Furthermore, our mapping efforts have identified plausible candidate genes for further study, one of which is SPOP. The identification of the causal variants of the gene is likely to clarify the molecular mechanisms underlying gliomagenesis (17). So far, the prevalence of decreased SPOP expression has not been extensively reported in glioma, especially with regard to the effect of decreased SPOP expression in glioma. Here, in this study, we surveyed the expression of SPOP in human patient samples. To explore its associated molecular mechanisms in glioma cells, we examined the effect of targeted overexpression of SPOP gene on cell viability, migration and invasion in vitro. These studies will be useful in identifying potential candidates for targeted therapeutic intervention of glioma.

\section{Materials and methods}

Human tissue samples. A total of 98 paraffin-embedded glioma and $12 \mathrm{NB}$ tissues samples were obtained from patients who underwent surgical treatment at Xiangya Hospital during the period from January 2005 to January 2010 . These patients or their legal guardian provided written informed consent to the surgical procedures and gave permission to use resected tissue specimens for research purposes. A diagnosis of glioma was confirmed pathologically by two independent, experienced pathologists. All specimens had confirmed pathological diagnosis and were classified according to the World Health Organization (WHO) criteria. The follow-up data of the glioma patients in this study are available and complete. Overall survival, which was defined as the time from the operation to the time of patient death or the last follow-up, was used as a measure of prognosis. Postoperative follow-up occurred at our outpatient department and included clinical and laboratory examinations every 3 months for the first 2 years, every 6 months during the 3 rd to 5 th years, annually for an additional 5 years or until patient death, whichever occurred first.

Cell culture and transfection. Human glioma cell strains of U87 and U251 were purchased from a cell bank at the Chinese Academy of Sciences and grown in Dulbecco's modified Eagle's medium (DMEM) (Hyclone, Logan, UT, USA) supplemented with $10 \%$ fetal calf serum (Gibco, Grand Island, NY, USA). All cell lines were cultured at $37^{\circ} \mathrm{C}$ in a humidified atmosphere of $5 \% \mathrm{CO}_{2}$. Transfection reagent Lipofectamine 3000 was purchased from Invitrogen (St. Louis, MO, USA). For overexpression of SPOP, the full-length SPOP cDNA was amplified and cloned into the pCDNA3.1(+) expression vector (Invitrogen; Life Technologies). U87 and U251 cells were then transfected with a negative empty vector or a SPOP expressing plasmid using Lipofectamine 3000 according to the manufacturer's instructions. Cells were collected after $48-72 \mathrm{~h}$ for further experiments.

Real-time quantitative PCR. Total RNA was extracted from tissues lysate using a TRIzol kit (Invitrogen, Carlsbad, CA,
USA), and cDNA was subsequently synthesized from total RNA using an Omniscript RT kit (Qiagen, Valencia, CA, USA) following the supplier's instructions. For detecting the mRNA level of SPOP, quantitative real-time PCR was conducted on the Mastercycler ep realplex (Eppendorf 2S, Hamburg, Germany). A $25-\mu 1$ reaction mixture contained $1 \mu \mathrm{l}$ of cDNA from samples, $12.5 \mu \mathrm{l}$ of $2 \mathrm{X}$ Fast EvaGreen ${ }^{\mathrm{TM}}$ qPCR Master Mix (Biotium Inc., Hayward, CA, USA), $1 \mu 1$ primers (10 mM), and $10.5 \mu \mathrm{l}$ of RNase/DNase-free water. PCR procedures: incubation at $96^{\circ} \mathrm{C}$ for $2 \mathrm{~min}, 40$ cycles at $96^{\circ} \mathrm{C}$ for $15 \mathrm{sec}$ and $60^{\circ} \mathrm{C}$ for $1 \mathrm{~min}$. The $\mathrm{Ct}$ value was defined as the cycle number at which the fluorescence intensity reached a certain threshold where amplification of each target gene was within the linear region of the reaction amplification curves. Relative expression level for each target gene was normalized by the $\mathrm{Ct}$ value of $\beta$-actin (internal control) using a $2^{-\Delta \Delta \mathrm{Ct}}$ relative quantification method. The sequences of the primers for SPOP are as follows: SPOP forward, 5'-TGACCACCAGGTAGACAGCG-3'; SPOP reverse, 5'-CCCGTTTCCCCCAAGTTA-3'. The $\beta$-actin gene served as an internal control. The sequences of the primers for $\beta$-actin are as follows: $\beta$-actin forward, 5'-AACTTCCGTTGCTGCCAT-3'; $\beta$-actin reverse, 5 '-TTT CTTCCACAGGGCTTTG-3'. The $2^{-\Delta \Delta C t}$ method was used to calculate relative changes in gene expression.

Western blot analysis. The homogenized glioma cancer samples, including tumor and nomal brain tissues, as well as cell lines, were lysed in RIPA lysis buffer, and the lysates were harvested by centrifugation $(12,000 \mathrm{rpm})$ at $4^{\circ} \mathrm{C}$ for $20 \mathrm{~min}$. Approximately $20 \mu \mathrm{g}$ protein samples were then separated by electrophoresis in a $12 \%$ sodium dodecyl sulfate polyacrylamide gel and transferred onto a polyvinylidene fluoride membrane. After blocking the non-specific binding sites for $60 \mathrm{~min}$ with $5 \%$ non-fat milk, the membranes were incubated overnight at $4^{\circ} \mathrm{C}$ with a goat polyclonal antibody against SPOP $(1: 500$, sc-66649, Santa Cruz Biotechnology, USA). The membranes were then washed three times with TBST (Tris-buffered saline with Tween-20) for $10 \mathrm{~min}$ and probed with the horseradish peroxidase (HRP)-conjugated donkey anti-goat IgG antibody (1:2,000, Immunology Consultants Laboratory, USA) at $37^{\circ} \mathrm{C}$ for $1 \mathrm{~h}$. After three washes, the membranes were developed by an enhanced chemiluminescence system (Cell Signaling Technology, Danvers, MA, USA). The band intensity was measured by densitometry using the Quantity One software (Bio-Rad Laboratories, Inc. Hercules, CA, USA). The protein levels were normalized to $\beta$-actin.

Immunohistochemistry analysis. The tissue sections were deparaffinized with dimethylbenzene and rehydrated with $100,95,90,80,70$ and $50 \%$ ethanol. After three washes in phosphate-buffered saline (PBS), the slides were boiled in antigen retrieval buffer containing $0.01 \mathrm{M}$ sodium citratehydrochloric acid (pH 6.0) for $15 \mathrm{~min}$ in a microwave oven. After rinsing with PBS, the tissue sections were incubated with goat polyclonal anti-human SPOP antibody (1:100, sc-66649, Santa Cruz Biotechnology, Inc., USA) and then rinsed in 3\% peroxidase quenching solution (Invitrogen) to block endogenous peroxidase. The sections were then incubated with a donkey anti-goat second antibody conjugated horseradish peroxidase (1:5,000; Abcam, Cambridge, UK) at $4^{\circ} \mathrm{C}$ overnight 

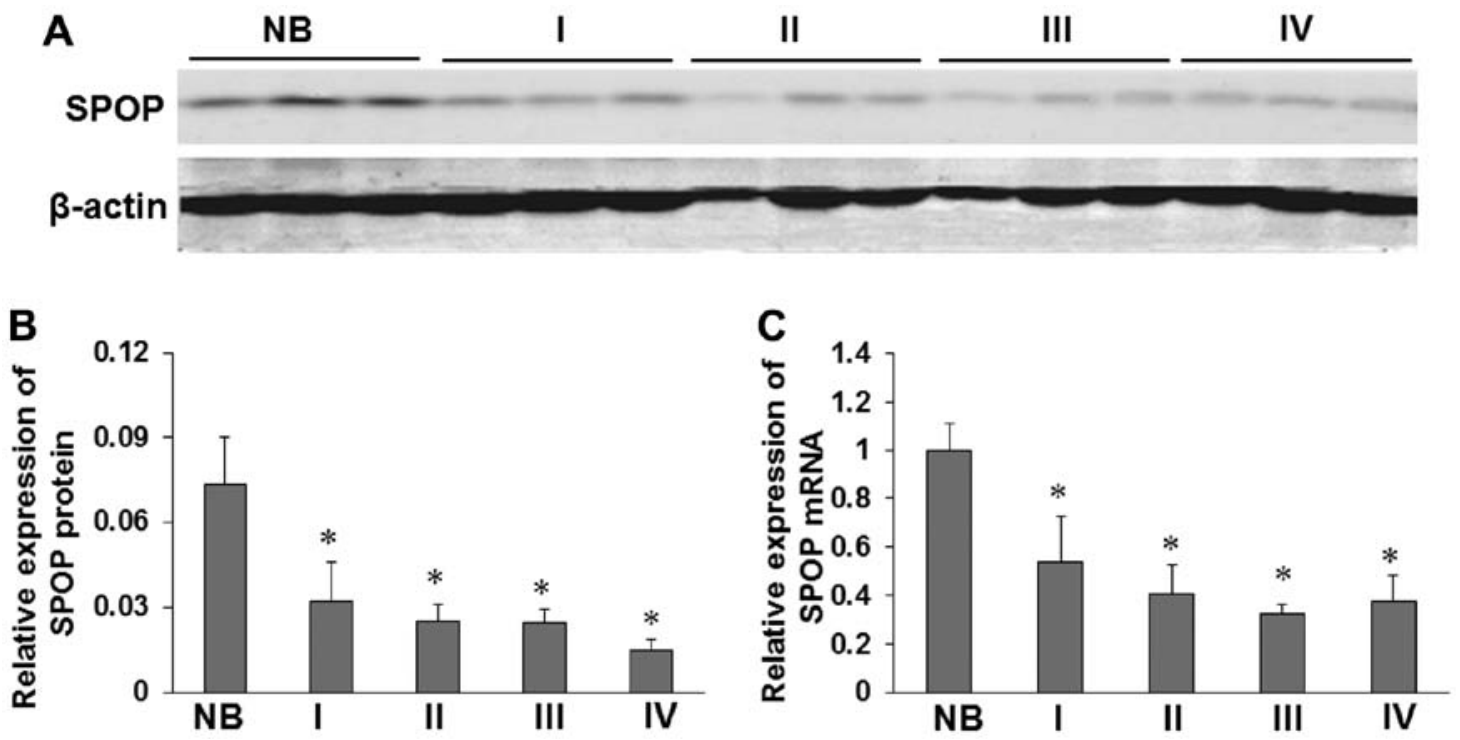

Figure 1. (A and B) Western blot analysis revealed a low level of expression of SPOP in gliomas. $\beta$-actin was assessed as a loading control. Lanes NB, human normal brain tissue; lanes I, II, III and IV represent glioma grades, respectively. (C) qRT-PCR analysis revealed a low level of expression of SPOP in gliomas. $\mathrm{N}$, normal brain tissue; I, II, III and IV represent glioma grades, respectively ( ${ }^{*} \mathrm{P}<0.05$ compared to normal brain tissues).

and after washing in PBS, the visualization signal was developed with 3, 3'-diaminobenzidine (DAB) solution, and all of the slides were counterstained with hematoxylin. As negative controls, adjacent sections were processed as described above except that they were incubated overnight at $4^{\circ} \mathrm{C}$ in blocking solution without the primary antibody. The specimens were analyzed by two observers who were blinded to the patients' clinical outcomes. Discrepancies between the observers were found in $<10 \%$ of the examined slides, and a consensus was reached after further review. The total SPOP immunostaining score was calculated as the sum of the percentage of positively stained tumor cells and the staining intensity and ranged from 0 to 9 . Briefly, the percentage of positive staining was scored as 0 (0-9\%, negative), 1 (10-25\%, sporadic), 2 (26-50\%, focal) or $3(51-100 \%$, diffuse), and the intensity was scored as 0 (no staining), 1 (weak staining), 2 (moderate staining) or 3 (strong staining). The expression level of SPOP was defined as follows: '-' (negative, score of 0 ), ' + ' (weakly positive, score of 1-3), '++' (positive, score of 4-6), '+++' (strongly positive, score of 7-9). We defined strong SPOP expression as a total score of $>3$, and weak SPOP expression as a total score of $\leq 3$.

Cell viability and proliferation assay. The tetrazolium-based cell viability (MTT) assay was performed to test cell proliferation. Cells transfected SPOP plasmid or empty vector were seeded in a 96-well plate at $1 \times 10^{3}$ cells/well, $100 \mu 1$ of sterile MTT dye $(0.5 \mathrm{mg} / \mathrm{ml}$, Sigma $)$ was added to each well and cultured for another $4 \mathrm{~h}$. The supernatant was discarded and then $150 \mu \mathrm{l}$ of dimethyl sulphoxide (DMSO) (Sigma, St. Louis, MO, USA) was added to each well, the spectrophotometric absorbance was measured for each sample at $490 \mathrm{~nm}$, all the experiments were performed in triplicate and repeated 3 times, and the average was calculated.

Cell migration assays. The cell migratory capacity was determined using transwell chambers (Corning, Corning, NY, USA). Briefly, cells (1x10 $/$ well) were suspended in $100 \mu \mathrm{l}$ serum-free medium and then added to the upper chamber of the inserts, DMEM medium (Gibco) containing 10\% FBS $(500 \mu \mathrm{l})$ was added to the lower chamber as the chemotactic factor. After culture for $24 \mathrm{~h}$ at $37^{\circ} \mathrm{C}$, non-migrated cells on the upper surface were removed gently with a cotton swab and cells that migrated to the lower side of the department were fixed and dyed with $0.1 \%$ crystal violet. The number of migrated cells were calculated by counting five different views by microscopy. Independent experiments were repeated three times, with triplicates in each experiment.

Statistical analysis. All quantified data represent an average of at least triplicate samples. SPSS 18.0 (SPSS Inc, Chicago, IL, USA) was used for statistical analysis. Data are presented as mean \pm SD. One-way ANOVA or two-tailed Student's t-test was used for comparisons between groups. Chi-square test or Fischer's were used to identify differences between categorical variables. Survival analysis was performed using Kaplan-Meier method. Multivariate Cox proportional hazards method was used for analyzing the relationship between the variables and patient's survival time. Values of $\mathrm{P}<0.05$ were considered to indicate statistically significant results in all cases.

\section{Results}

Downregulated expression of SPOP gene in glioma tissues. In order to assess the role of SPOP in glioma, we performed western blotting and real-time PCR to measure the expression of SPOP in 35 freshly collected glioma tissues and 12 freshly collected NB tissues. SPOP protein was found to be markedly downregulated in 24 cases of glioma (WHO I-IV) compared with $6 \mathrm{NB}$ tissues with an increase in pathologic grade of the brain gliomas $(\mathrm{P}<0.05$, Fig. 1A and $\mathrm{B})$. Compared with NB tissues, glioma tissues exhibited lower expression levels of SPOP mRNA $(\mathrm{P}<0.05)$ (Fig. 1C). We also measured the expression levels and subcellular localization of SPOP protein 

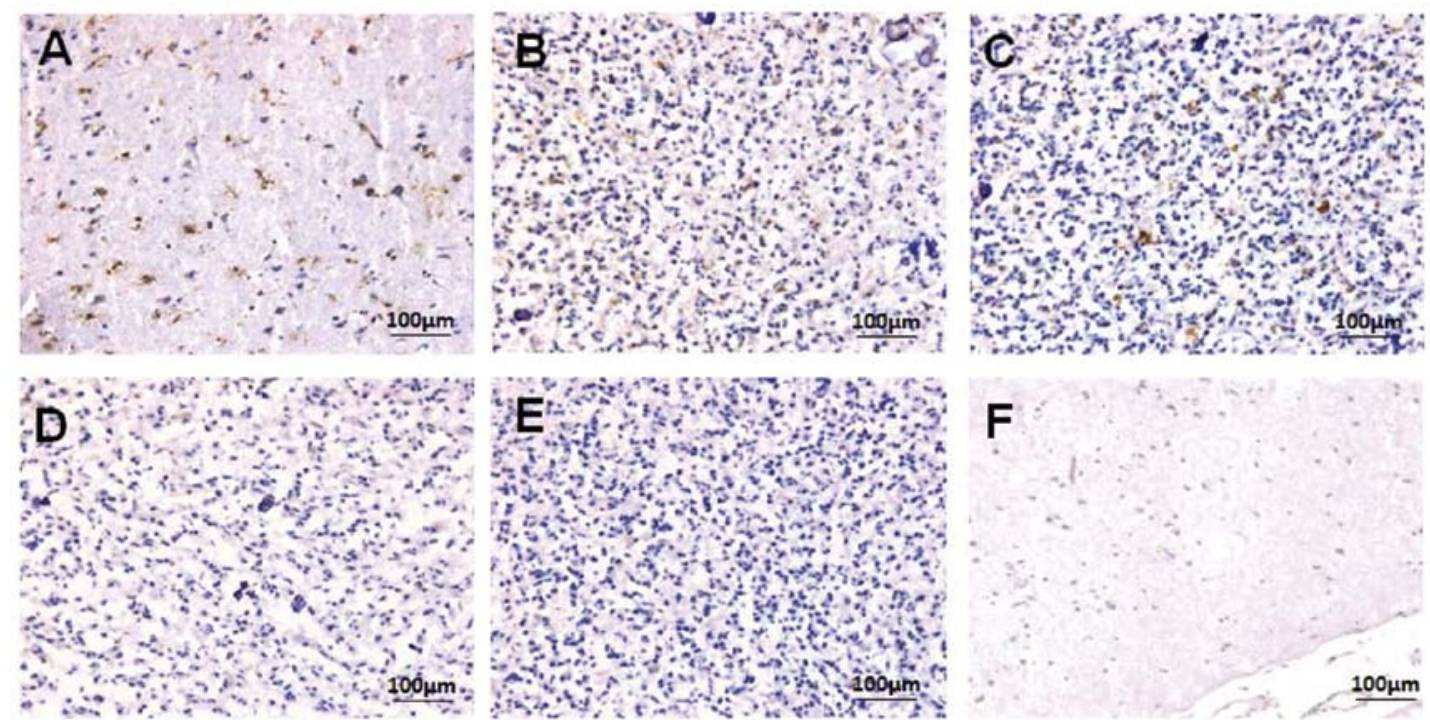

Figure 2. Immunohistochemical expression of SPOP in glioma specimens of different grades. SPOP immunoreactivity shows homogeneous brown-yellow staining in the cytoplasm of tumor cells; hematoxylin counterstain. (A) Normal brain tissue. (B) Grade I. (C) Grade II. (D) Grade III; (E) Grade IV. (F) Negative control. Original magnification, $\mathrm{x} 200$. With increasing pathologic grade, the SPOP expression in human gliomas were significantly decreased $(\mathrm{P}<0.05$ compared with normal brain).

A
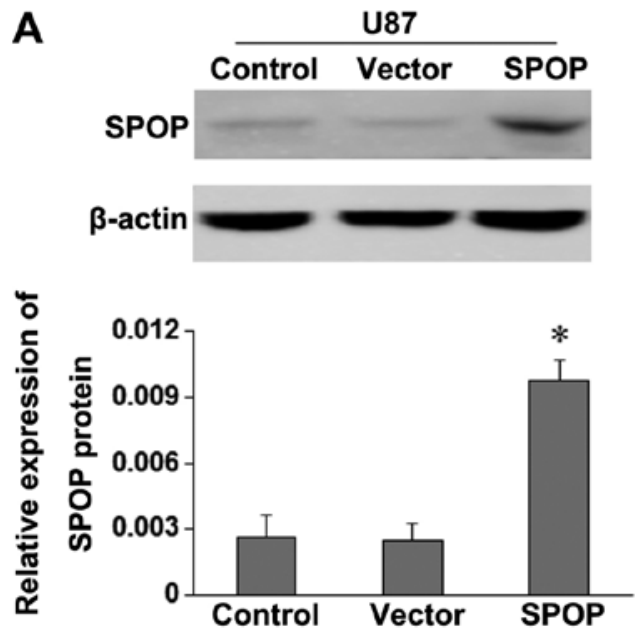

B
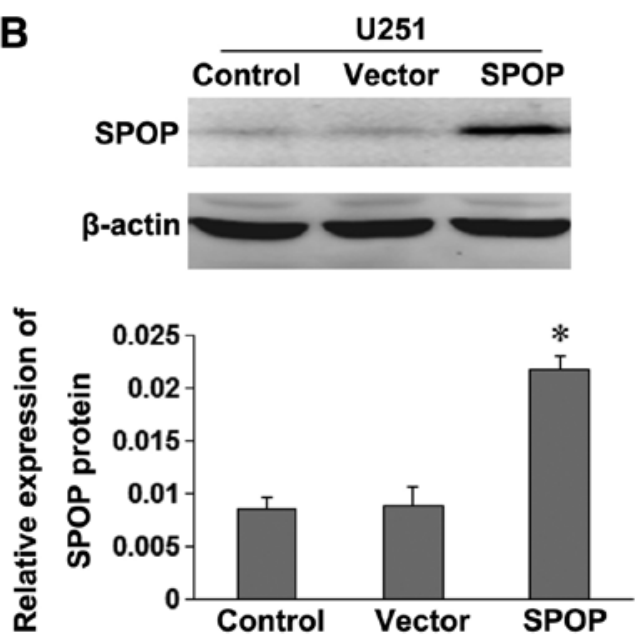

Figure 3. Western blot analysis displays a significant increase of SPOP in pCDNA3.1-SPOP transfected cells (SPOP) compared to control or empty vector transfected groups. $\beta$-actin was assessed as a loading control. The data for SPOP overexpression are based on cell line U87 (A) and U251 (B).

in 98 archived paraffin-embedded glioma samples and 12 NB tissues using immunohistochemical staining (Fig. 2). SPOP protein showed low expression in $62.2 \%$ (61/98) of glioma samples, while high expression in $75 \%(9 / 12)$ of NB samples, and the difference was statistically significant $(\mathrm{P}=0.014$; Table I).

The correlations between the expression of SPOP and various clinicopathological characteristics. The relationship between clinicopathological characteristics and SPOP expression levels in individuals with glioma were analyzed by the Chi-square analysis. We found no significant association between SPOP expression levels and the patient age, gender, increased ICP, cystic change, tumor necrosis, resection degree, chemotherapy or radiotherapy in the 98 glioma cases. However, we observed that the expression level of SPOP was positively correlated
Table I. SPOP expression compared in glioma and NB tissues.

\begin{tabular}{|c|c|c|c|c|}
\hline \multirow[b]{2}{*}{ Group } & \multirow[b]{2}{*}{$\begin{array}{l}\text { Value } \\
\text { (n) }\end{array}$} & \multicolumn{2}{|c|}{ Expression } & \multirow[b]{2}{*}{ P-value } \\
\hline & & $\begin{array}{c}\text { Low } \\
\text { expression (n) }\end{array}$ & $\begin{array}{c}\text { High } \\
\text { expression (n) }\end{array}$ & \\
\hline Glioma & 98 & 61 & 37 & 0.014 \\
\hline Normal & 12 & 3 & 9 & \\
\hline
\end{tabular}

$\mathrm{P}$-value $<0.05$ was considered statistically significant.

with mean tumor diameter $(\mathrm{MTD})(\mathrm{P}=0.021)$ and the status of tumor grade and histological type (WHO I, II, III and IV) $(\mathrm{P}=0.032)$ in glioma patients (Table II). 
Table II. Correlation between the clinicopathological characteristics and expression of SPOP in glioma.

\begin{tabular}{|c|c|c|c|c|}
\hline Characteristics & Value (n) & $\begin{array}{c}\text { SPOP expression } \\
\text { Low }(n)\end{array}$ & $\begin{array}{c}\text { SPOP expression } \\
\text { High }(\mathrm{n})\end{array}$ & P-value \\
\hline Gender & -98 & 61 & 37 & 0.421 \\
\hline Male & 58 & 38 & 20 & \\
\hline Female & 40 & 23 & 17 & \\
\hline Age & & & & 0.752 \\
\hline$\leq 50$ & 31 & 20 & 11 & \\
\hline$>50$ & 67 & 41 & 26 & \\
\hline $\operatorname{MTD}(\mathrm{cm})$ & & & & $0.021^{\mathrm{a}}$ \\
\hline$\leq 5$ & 41 & 31 & 10 & \\
\hline$\geq 5$ & 57 & 30 & 27 & \\
\hline Increased ICP & & & & 0.226 \\
\hline No & 63 & 42 & 21 & \\
\hline Yes & 35 & 19 & 16 & \\
\hline Cystic change & & & & 0.578 \\
\hline No & 71 & 43 & 28 & \\
\hline Yes & 27 & 18 & 9 & \\
\hline Tumor necrosis & & & & 0.136 \\
\hline No & 79 & 52 & 27 & \\
\hline Yes & 19 & 9 & 10 & \\
\hline Resection degree & & & & 0.334 \\
\hline Gross total resection & 80 & 48 & 32 & \\
\hline Subtotal resection & 18 & 13 & 5 & \\
\hline Tumor grade and histological type & & & & $0.032^{\mathrm{a}}$ \\
\hline \multicolumn{5}{|l|}{ WHO grade I } \\
\hline Pilocytic astrocytoma & 14 & 9 & 5 & \\
\hline \multicolumn{5}{|l|}{ WHO grade II } \\
\hline Astrocytoma & 19 & 16 & 3 & \\
\hline Oligodendroglioma & 7 & 4 & 3 & \\
\hline \multicolumn{5}{|l|}{ WHO grade III } \\
\hline Anaplastic astrocytoma & 25 & 18 & 7 & \\
\hline \multicolumn{5}{|l|}{ WHO grade IV } \\
\hline Glioblastoma multiforme & 33 & 14 & 19 & \\
\hline Chemotherapy & & & & 0.176 \\
\hline No & 15 & 7 & 8 & \\
\hline Yes & 83 & 54 & 29 & \\
\hline Radiotherapy & & & & 0.384 \\
\hline No & 17 & 9 & 8 & \\
\hline Yes & 81 & 52 & 29 & \\
\hline
\end{tabular}

${ }^{\text {ap}} \mathrm{P}$-value $<0.05$ was considered statistically significant.

The role of SPOP in proliferation and migration in the cell lines. Because our above results indicated that SPOP expression was reduced in glioma and that SPOP might act as a tumor suppressor, we next tried to explore the function of SPOP in glioma development. To evaluate the effects of SPOP on cell viability, the SPOP expression vector or the empty vector were, respectively, transfected into U87 and U251 cells. SPOP expression in transfected cells were detected by western blotting (Fig. 3). The expression of SPOP protein in pCDNA3.1SPOP group (SPOP) was significantly higher than control and 

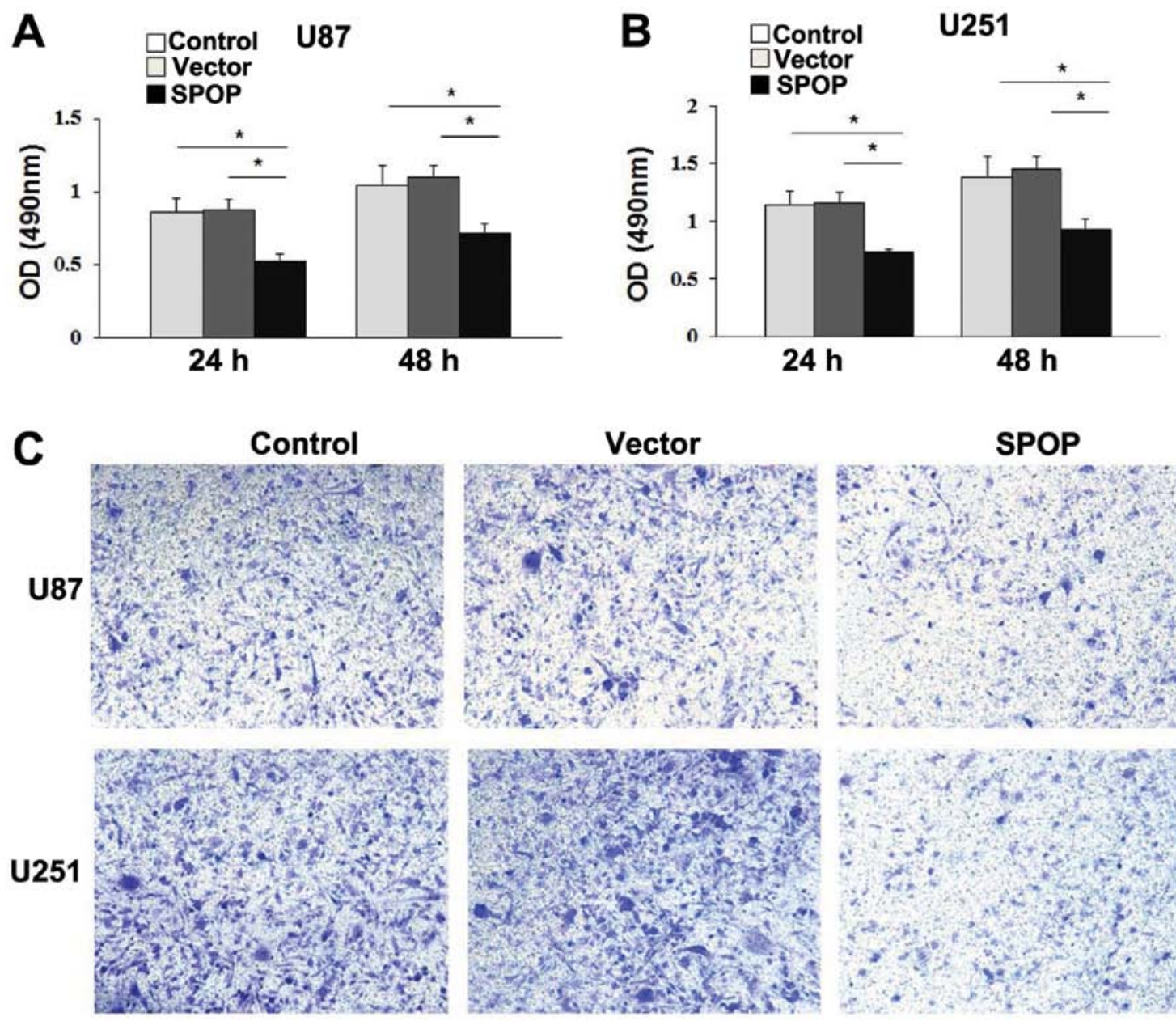

D
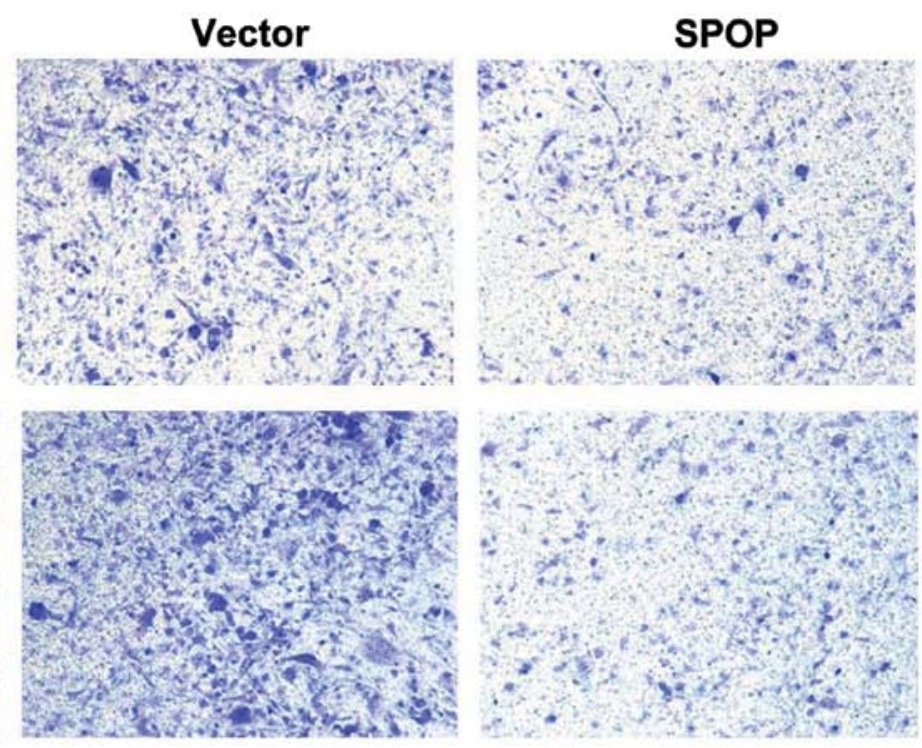

U87
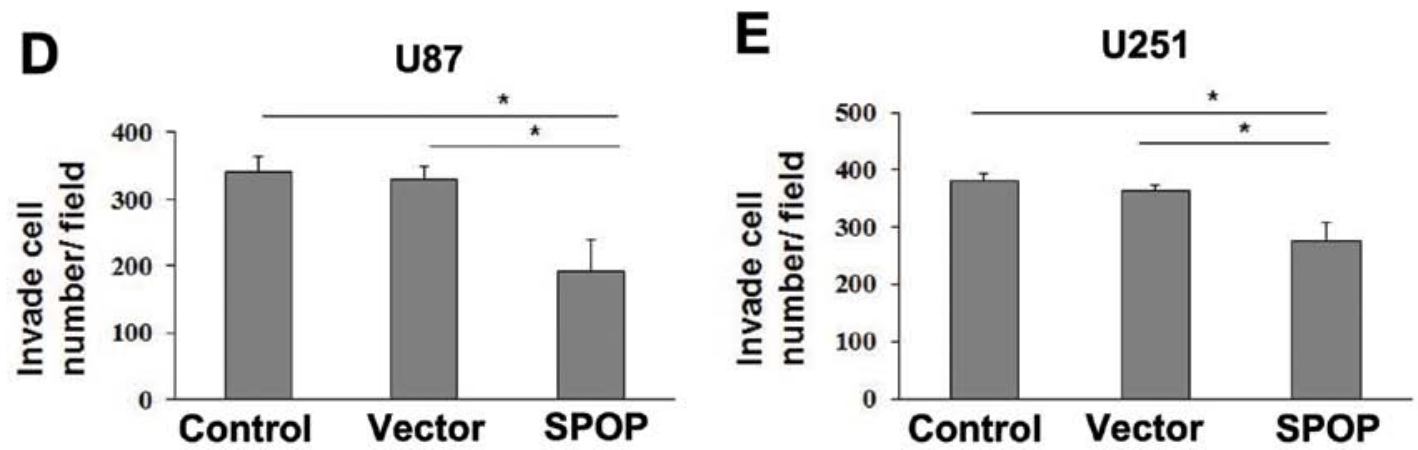

Figure 4. (A and B) Overexpression of SPOP inhibits cell proliferation in U87 and U251 cells ("P<0.05). Cell vitality was evaluated with the MTT assay using absorbance readings at $490 \mathrm{~nm}$. The values shown are the mean of three determinations. (C-E) Overexpression of SPOP inhibits cell migration in U87 and $\mathrm{U} 251$ cells as demonstrated by transwell assays ( $\mathrm{P}<0.01)$. Representative images of stained cells are shown with the original magnification of $\mathrm{x} 100$.

empty vector groups. The cell growth by MTT assay revealed that cell growth rate in SPOP-transfected glioma cells were significantly lower than control or empty vector-transfected glioma cells (Fig. 4A and B, P<0.05), which showed that SPOP significantly repressed the viability of glioma cells.

We evaluated the potential role of SPOP on cellular migration by transwell assays. U87 and U251 cells were transfected with SPOP overexpressing or empty vector plasmid and their migratory abilities were determined $24 \mathrm{~h}$ later. The results showed overexpression of SPOP was associated with a significant reduction of migration compared to the empty vector (Fig. 4C-E, P<0.01).
These findings were further confirmed by the wound healing assay. The overexpression of SPOP significantly inhibited the migration of U87 and U251 cells at $48 \mathrm{~h}$ after transfection (Fig. 5, P<0.05).

Expression of SPOP and clinical outcome. The overall survival of patients with low SPOP expression was significantly worse than that of SPOP-high patients $(\mathrm{P}=0.001, \log$-rank test, Fig. 6). Univariate Cox regression analyses showed that MTD and SPOP expression were significantly associated with overall survival (Table III). Furthermore, a multivariate Cox regression analysis confirmed the MTD and SPOP expression 
A
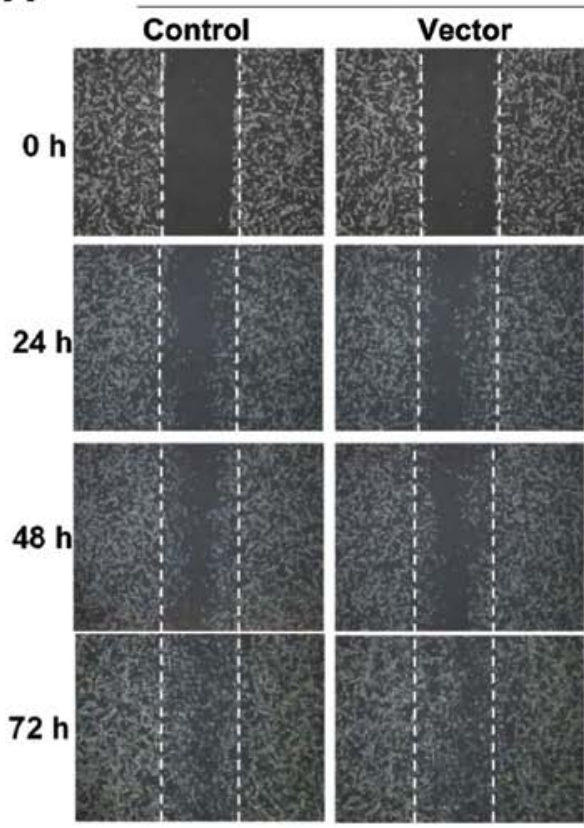

C
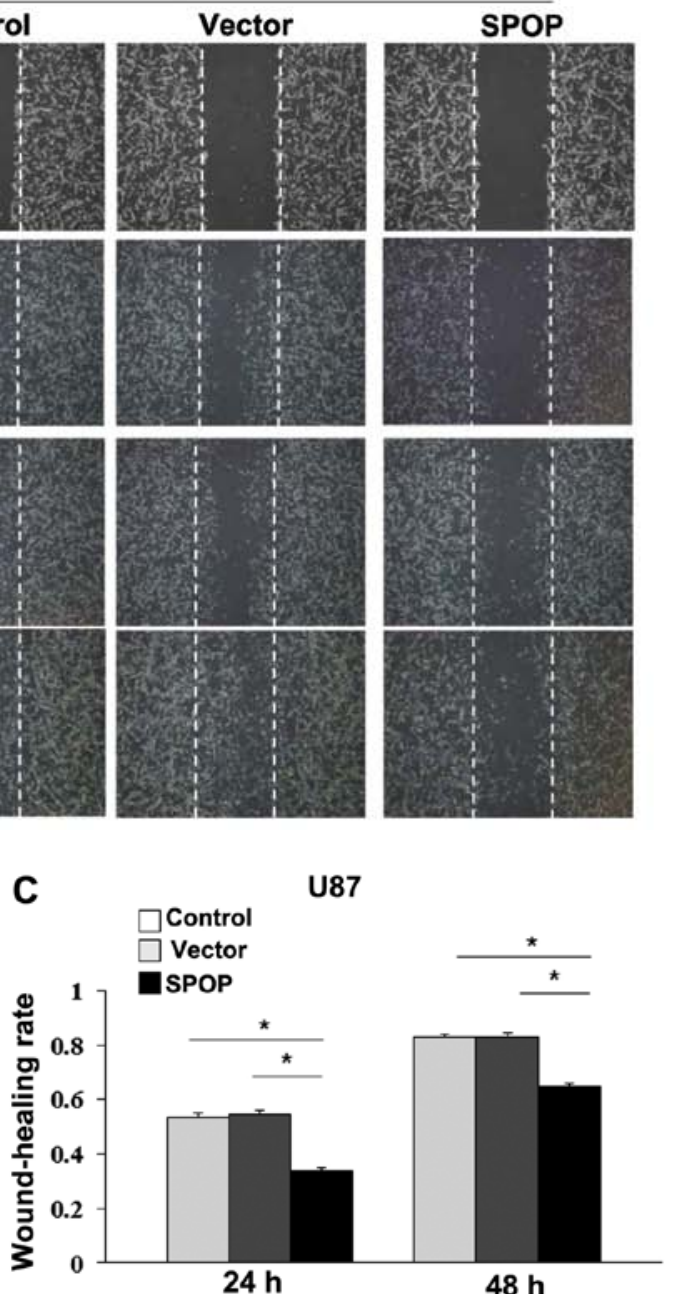

B

$48 \mathrm{~h}$

$\mathbf{O h}$

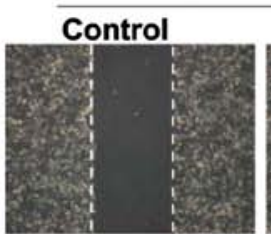

U251
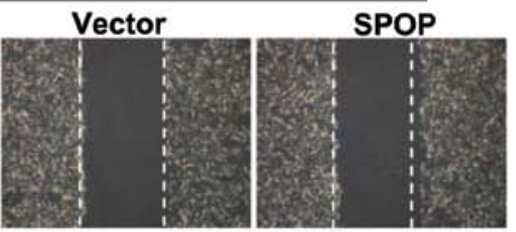

$24 \mathrm{~h}$
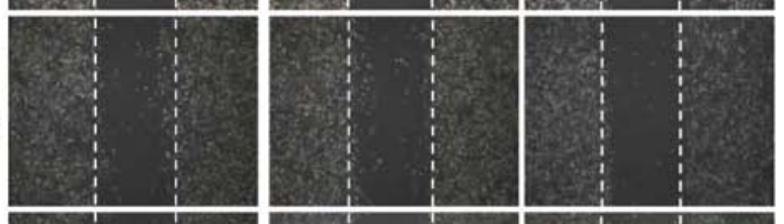

$72 \mathrm{~h}$
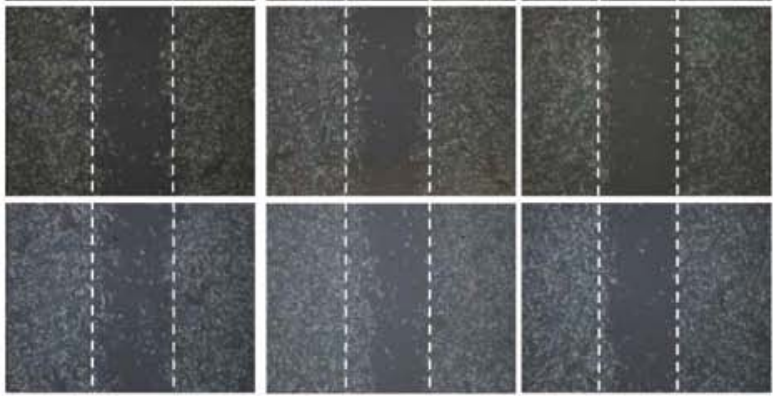

D

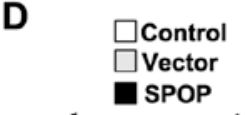

U251

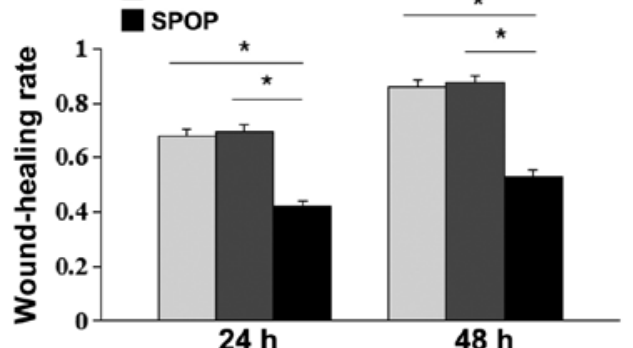

Figure 5. Wound-healing assay. U87 and U251 cells were transfected with pcDNA3.1-SPOP (SPOP), empty vector and control groups for 0, 24, 48 and $72 \mathrm{~h}$, respectively. The migration capacity was significantly decreased in the pcDNA3.1-SPOP transfected group compared with the empty vector and control groups (magnification, $\mathrm{x} 40)(\mathrm{P}<0.05$ compared to empty vector or control group).

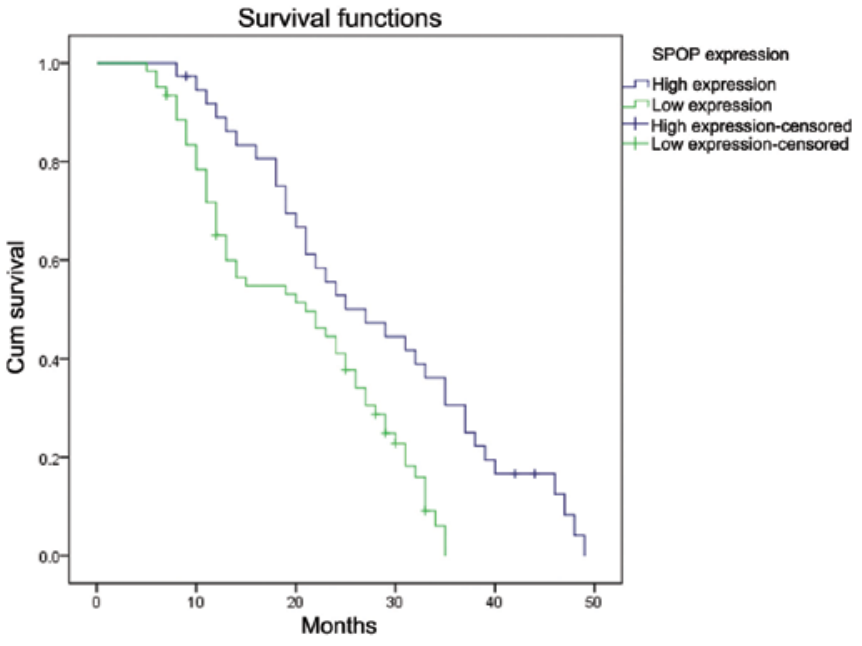

Figure 6. Kaplan-Meier curves for OS in glioma cancer patients with low level and high level SPOP expression $(\mathrm{P}=0.001)$.

as independent predictors of the overall survival of glioma cancer patients (Table III).

\section{Discussion}

Glioma, the most common type of primary brain tumors in adults, is subcategorized by histopathologic evaluation and clinical criteria into four grades (I-IV), according to the current World Health Organization (WHO) guidelines (18). Despite multimodal treatment including surgery, chemotherapy and radiation, the average survival time of glioma patients is 10-14 months after diagnosis in the last 5 years (19). The extremely poor prognosis of these patients may be due to the biological characteristics of glioma cells which include unrestricted proliferation and extensive invasion (20). Therefore, understanding the main molecular mechanisms of this malignancy is the key for the development of novel and effective therapeutic strategies for glioma. In this study, we investigated the expression of speckle-type POZ domain protein (SPOP) in glioma. We found that the expression of SPOP was significantly reduced at both mRNA and protein levels in glioma compared with normal brain tissues. We also found that glioma patients with low expression of SPOP showed shorter postsurgical survival than high SPOP expression patients. Notably, we show for the first time that SPOP is expressed in normal brain, supporting further 
Table III. Univariate and multivariate analyses of overall survival of glioma patients.

\begin{tabular}{|c|c|c|c|c|c|c|}
\hline \multirow[b]{2}{*}{ Variables } & \multicolumn{2}{|c|}{ Univariate analysis } & \multirow[b]{2}{*}{ P-value } & \multicolumn{2}{|c|}{ Multivariate analysis } & \multirow[b]{2}{*}{ P-value } \\
\hline & HR & $95 \% \mathrm{CI}$ & & HR & $95 \% \mathrm{CI}$ & \\
\hline Gender (male vs female) & 2.138 & $1.437-3.516$ & 0.132 & 2.053 & $1.267-3.326$ & 0.223 \\
\hline Age $(\leq 50$ vs $>50)$ & 0.842 & $0.433-1.668$ & 0.460 & 0.765 & $0.384-1.537$ & 0.414 \\
\hline $\operatorname{MTD}(\mathrm{cm})(\leq 5 \mathrm{vs} \geq 5)$ & 1.031 & $0.716-1.514$ & $0.034^{\mathrm{a}}$ & 1.329 & $0.887-1.915$ & $0.027^{\mathrm{a}}$ \\
\hline Increased ICP (no vs yes) & 0.977 & $0.606-1.575$ & 0.942 & 1.227 & $0.749-1.908$ & 0.417 \\
\hline Cystic change (no vs yes) & 0.525 & $0.342-0.805$ & 0.287 & 0.611 & $0.393-0.950$ & 0.512 \\
\hline Tumor necrosis (no vs yes) & 0.546 & $0.316-0.944$ & 0.430 & 0.445 & $0.268-0.739$ & 0.362 \\
\hline \multicolumn{7}{|l|}{ Resection degree } \\
\hline (gross total vs subtotal) & 0.616 & $0.391-1.004$ & 0.183 & 0.624 & $0.387-1.078$ & 0.112 \\
\hline WHO (I vs II vs III vs IV) & 2.118 & $1.328-3.379$ & 0.142 & 2.896 & $1.719-4.878$ & 0.131 \\
\hline Chemotherapy (no vs yes) & 0.896 & $0.787-1.106$ & 0.357 & 0.799 & $0.689-1.010$ & 0.610 \\
\hline Radiotherapy (no vs yes) & 0.832 & $0.743-1.018$ & 0.474 & 0.762 & $0.613-1.008$ & 0.762 \\
\hline \multicolumn{7}{|l|}{ SPOP expression } \\
\hline (low vs high) & 0.548 & $0.346-0.893$ & $0.018^{\mathrm{a}}$ & 0.439 & $0.298-0.764$ & $0.012^{\mathrm{a}}$ \\
\hline
\end{tabular}

${ }^{\text {aP-value }}<0.05$ was considered statistically significant.

research on the potential role of SPOP in brain development. Instead, our data, obtained by modulating SPOP expression, establish a role for SPOP in modulating the biological properties of glioma cells, including proliferation, migration and in vitro aggressiveness. Overexpression of SPOP resulted in suppression of cell proliferation, arrest of cell migration. This evidence suggests a potential role for SPOP in the regulation of glioma cell growth and proliferation which are in agreement with previous studies (11).

In humans, the roles for SPOP in regulating the $\mathrm{Hh}$ and TNF pathways have been conserved $(21,22)$, and several other SPOP substrates have been identified as well, including the death domain-associated protein (Daxx) (5), the polycomb group protein BMI-1, the phosphatidylinosital phosphate kinase PIPKII $\beta$ (23), the transcription factor Gli (24), the Jun-kinase phosphatase Puckered (14) and Pdx1 (25), and the histone variant MacroH2A (4). Together, these previous results indicate that SPOP plays important roles during cell apoptosis, proliferation, and animal development. Many proteins implicated in the ubiquitin pathways are related to tumor progression. In recent years, there have been many approaches to target the ubiquitin system in cancer therapy $(26,27)$. The E3 ubiquitin ligases are considered the most important components in these approaches because they bind directly to the target proteins (26). In the present study, we evaluated the role of SPOP as an adaptor in the Cullin3-based E3 ubiquitin ligase complex, which indicated that SPOP might play a role in tumorigenesis as a tumor suppressor gene. Moreover, our experimental results from breast cancer cell proliferation, invasion, anchorage-independent growth, and tumor growth in nude mice indicate that SPOP inhibits cancer cell functions. We also found that shRNA knockdown of SPOP in MDA-MB-231 cells increases cancer cell size (11), consistent with previous reports (28).

Considering pro-apoptotic and other tumor-suppressive functions of SPOP identified in earlier studies $(11,29)$, we suggest that downregulation of SPOP in the cancers compared with normal cells might possibly decrease its functions as a tumor suppressor gene and might contribute to cancer development. Although most of the identified functions of SPOP are related to tumor suppression, there is evidence that SPOP serves as a regulatory hub to promote clear cell renal cell carcinoma (ccRCC) tumorigenesis suggesting a possibility that tumor-related functions of SPOP might vary depending on tissue and cellular contexts (30). However, in this study, we have reasons to believe that SPOP could be a new therapeutic target for improving the treatment efficiency of glioma.

In conclusion, in this study, we investigated the role of SPOP in human glioma for the first time. Our results suggested that SPOP was downexpressed in glioma compared with normal brain tissues, and low expression of SPOP was significantly associated with poorer overall survival. Additionally, we provide compelling evidence that overexpression of SPOP leads to suppressed cell viability, migration and invasion in glioma cell lines in vitro. SPOP expression may have significant value as an unfavorable progression indicator for glioma patients.

\section{References}

1. Louis DN: Molecular pathology of malignant gliomas. Annu Rev Pathol 1: 97-117, 2006.

2. Stupp R, Hegi ME, Mason WP, van den Bent MJ, Taphoorn MJ, Janzer RC, Ludwin SK, Allgeier A, Fisher B, Belanger K, Hau P, Brandes AA, Gijtenbeek J, Marosi C, Vecht CJ, Mokhtari K, Wesseling P, VillaS, EisenhauerE, Gorlia T, Weller M,LacombeD, Cairncross JG, Mirimanoff RO; European Organisation for Research and Treatment of Cancer Brain Tumour and Radiation Oncology Groups; National Cancer Institute of Canada Clinical Trials Group: National Cancer Institute of Canada Clinical Trials Group: Effects of radiotherapy with concomitant and adjuvant temozolomide versus radiotherapy alone on survival in glioblastoma in a randomised phase III study: 5-year analysis of the EORTC-NCIC trial. Lancet Oncol 10: 459-466, 2009.

3. Nagai Y,Kojima T,Muro Y,Hachiya T,Nishizawa Y,Wakabayashi T and Hagiwara M: Identification of a novel nuclear speckle-type protein, SPOP. FEBS Lett 418: 23-26, 1997. 
4. Hernández-Muñoz I, Lund AH, van der Stoop P, Boutsma E Muijrers I, Verhoeven E, Nusinow DA, Panning B, Marahrens Y and van Lohuizen M: Stable X chromosome inactivation involves the PRC1 Polycomb complex and requires histone MACROH2A1 and the CULLIN3/SPOP ubiquitin E3 ligase. Proc Natl Acad Sc USA 102: 7635-7640, 2005

5. Kwon JE, La M, Oh KH, Oh YM, Kim GR, Seol JH, Baek SH, Chiba T, Tanaka K, Bang OS, Joe CO and Chung CH: BTB domain-containing speckle-type POZ protein (SPOP) serves as an adaptor of Daxx for ubiquitination by Cul3-based ubiquitin ligase. J Biol Chem 281: 12664-12672, 2006.

6. Kan Z, Jaiswal BS, Stinson J, Janakiraman V, Bhatt D, Stern HM, Yue P, Haverty PM, Bourgon R, Zheng J, Moorhead M, Chaudhuri S, Tomsho LP, Peters BA, Pujara K, Cordes S, Davis DP, Carlton VE, Yuan W, Li L, Wang W, Eigenbrot C, Kaminker JS, Eberhard DA, Waring P, Schuster SC, Modrusan Z, Zhang Z, Stokoe D, de Sauvage FJ, Faham M and Seshagiri S: Diverse somatic mutation patterns and pathway alterations in human cancers. Nature 466: 869-873, 2010.

7. Berger MF, Lawrence MS, Demichelis F, Drier Y, Cibulskis K, Sivachenko AY, Sboner A, Esgueva R, Pflueger D, Sougnez C, Onofrio R, Carter SL, Park K, Habegger L, Ambrogio L, Fennell T, Parkin M, Saksena G, Voet D, Ramos AH, Pugh TJ, Wilkinson J, Fisher S, Winckler W, Mahan S, Ardlie K, Baldwin J, Simons JW, Kitabayashi N, MacDonald TY, Kantoff PW, Chin L, Gabriel SB, Gerstein MB, Golub TR, Meyerson M, Tewari A, Lander ES, Getz G, Rubin MA and Garraway LA: The genomic complexity of primary human prostate cancer. Nature 470 : 214-220, 2011.

8. Barbieri CE, Baca SC, Lawrence MS, Demichelis F, Blattner M, Theurillat JP, White TA, Stojanov P, Van Allen E, Stransky N, Nickerson E, Chae SS, Boysen G, Auclair D, Onofrio RC, Park K, Kitabayashi N, MacDonald TY, Sheikh K, Vuong T, Guiducci C, Cibulskis K, Sivachenko A, Carter SL, Saksena G, Voet D, Hussain WM, Ramos AH, Winckler W, Redman MC, Ardlie K, Tewari AK, Mosquera JM, Rupp N, Wild PJ, Moch H, Morrissey C, Nelson PS, Kantoff PW, Gabriel SB, Golub TR, Meyerson M, Lander ES, Getz G, Rubin MA and Garraway LA: Exome sequencing identifies recurrent SPOP, FOXA1 and MED12 mutations in prostate cancer. Nat Genet 44: 685-689, 2012.

9. Le Gallo M, O'Hara AJ, Rudd ML, Urick ME, Hansen NF, O'Neil NJ, Price JC, Zhang S, England BM, Godwin AK, Sgroi DC; NIH Intramural Sequencing Center (NISC) Comparative Sequencing Program, Hieter P, Mullikin JC, Merino MJ and Bell DW: Exome sequencingof serous endometrial tumors identifies recurrent somatic mutations in chromatin-remodeling and ubiquitin ligase complex genes. Nat Genet 44: 1310-1315, 2012.

10. Ande SR, Chen J and Maddika S: The ubiquitin pathway: an emerging drug target in cancer therapy. Eur J Pharmacol 625: 199-205, 2009 .

11. Li C, Ao J, Fu J, Lee DF, Xu J, Lonard D and O'Malley BW: Tumor-suppressor role for the SPOP ubiquitin ligase in signaldependent proteolysis of the oncogenic co-activator SRC-3/AIB1. Oncogene 30: 4350-4364, 2011.

12. Nakayama KI and Nakayama K: Ubiquitin ligases: cell-cycle control and cancer. Nat Rev Cancer 6: 369-381, 2006.

13. Bode AM and Dong Z: Post-translational modification of $\mathrm{p} 53$ in tumorigenesis. Nat Rev Cancer 4: 793-805, 2004.

14. Kim MS, Je EM, Oh JE, Yoo NJ and Lee SH: Mutational and expressional analyses of SPOP, a candidate tumor suppressor gene, in prostate, gastric and colorectal cancers. APMIS 121: 626-633, 2013

15. Dahmane N, Sánchez P, Gitton Y, Palma V, Sun T, Beyna M, Weiner $\mathrm{H}$ and Ruiz i Altaba A: The Sonic Hedgehog-Gli pathway regulates dorsal brain growth and tumorigenesis. Development 128: 5201-5212, 2001
16. Liu J, Ghanim M, Xue L, Brown CD, Iossifov I, Angeletti C, Hua S, Nègre N, Ludwig M, Stricker T, Al-Ahmadie HA, Tretiakova M, Camp RL, Perera-Alberto M, Rimm DL, Xu T, Rzhetsky A and White KP: Analysis of Drosophila segmentation network identifies a JNK pathway factor overexpressed in kidney cancer. Science 323: 1218-1222, 2009.

17. Liu Y, Melin BS, Rajaraman P, Wang Z, Linet M, Shete S, Amos CI, Lau CC, Scheurer ME, Tsavachidis S, Armstrong GN, Houlston RS, Hosking FJ, Claus EB, Barnholtz-Sloan J, Lai R, Il'yasova D, Schildkraut J, Sadetzki S, Johansen C, Bernstein JL, Olson SH, Jenkins RB, LaChance D, Vick NA, Wrensch M, Davis F, McCarthy BJ, Andersson U, Thompson PA, Chanock S; Gliogene Consortium and Bondy ML: Insight in glioma susceptibility through an analysis of $6 \mathrm{p} 22.3,12 \mathrm{p} 13.33-12.1,17 \mathrm{q} 22-23.2$ and $18 \mathrm{q} 23$ SNP genotypes in familial and non-familial glioma. Hum Genet 131: 1507-1517, 2012.

18. Louis DN, Ohgaki H, Wiestler OD and Cavenee WK: WHO Classifcation of Tumours of the Central Nervous System. 4th edition. IARC Press, Lyon, 2007.

19. Van Meir EG, Hadjipanayis CG, Norden AD, Shu HK, Wen PY and Olson JJ: Exciting new advances in neuro-oncology: the avenue to a cure for malignant glioma. CA Cancer J Clin 60: 166-193, 2010.

20. Mrugala MM: Advances and challenges in the treatment of glioblastoma: a clinician's perspective. Discov Med 15: 221-230, 2013.

21. Zhang Q, Zhang L, Wang B, Ou CY, Chien CT and Jiang J: A hedgehog-induced BTB protein modulates hedgehog signaling by degrading $\mathrm{Ci} / \mathrm{Gli}$ transcription factor. Dev Cell 10: 719-729, 2006.

22. Zhuang M, Calabrese MF, Liu J, Waddell MB, Nourse A, Hammel M, Miller DJ, Walden H, Duda DM, Seyedin SN, Hoggard T, Harper JW, White KP and Schulman BA: Structures of SPOP-substrate complexes: insights into molecular architectures of BTB-Cul3 ubiquitin ligases. Mol Cell 36: 39-50, 2009.

23. Bunce MW, Boronenkov IV and Anderson RA: Coordinated activation of the nuclear ubiquitin ligase Cul3-SPOP by the generation of phosphatidylinositol 5-phosphate. J Biol Chem 283: 8678-8686, 2008.

24. Chen MH, Wilson CW, Li YJ, Law KK, Lu CS, Gacayan R, Zhang X, Hui CC and Chuang PT: Cilium-independent regulation of Gli protein function by Sufu in Hedgehog signaling is evolutionarily conserved. Genes Dev 23: 1910-1928, 2009.

25. Claiborn KC, Sachdeva MM, Cannon CE, Groff DN, Singer JD and Stoffers DA: Pcif1 modulates Pdx1 protein stability and pancreatic $\beta$ cell function and survival in mice. J Clin Invest 120: 3713-3721, 2010.

26. Hoeller D and Dikic I: Targeting the ubiquitin system in cancer therapy. Nature 458: 438-444, 2009.

27. Cohen $P$ and Tcherpakov M: Will the ubiquitin system furnish as many drug targets as protein kinases. Cell 143: 686-693, 2010.

28. Torres-Arzayus MI, Font de Mora J, Yuan J, Vazquez F, Bronson R, Rue M, Sellers WR and Brown M: High tumor incidence and activation of the PI3K/AKT pathway in transgenic mice define AIB1 as an oncogene. Cancer Cell 6: 263-274, 2004.

29. Byun B, Tak H and Joe CO: BTB/POZ domain of speckle-type POZ protein (SPOP) confers proapoptotic function in HeLa cells. Biofactors 31: 165-169, 2007.

30. Li G, Ci W, Karmakar S, Chen K, Dhar R, Fan Z, Guo Z, Zhang J, Ke Y, Wang L, Zhuang M, Hu S, Li X, Zhou L, Li X, Calabrese MF, Watson ER, Prasad SM, Rinker-Schaeffer C, Eggener SE, Stricker T, Tian Y, Schulman BA, Liu J and White KP: SPOP promotes tumorigenesis by acting as a key regulatory hub in kidney cancer. Cancer Cell 25: 455-468, 2014. 